\title{
Acute ventriculoperitoneal shunt malfunction following opening of the spinal subarachnoid space
}

\author{
Ghaffar Shokouhi
}

Published online: 29 January 2009

(C) Springer-Verlag 2009

This manuscript is an analysis of five patients with ventriculoperitoneal shunt malfunction following intradural lumbar spine operation. The authors attribute the cause of this shunt malfunction to the intracranial shunt catheter obstruction due to negative pressure at the lumbar site and cerebrospinal fluid drainage after lumbar subarachnoid space opening. Although the numbers are few, the speculation by the authors is insightful.
This phenomenon is similar to slit ventricles due to normal pressure valve overdrainage in which high-pressure valve replacement is necessary. Further studies on patients with programmable valves that provide the ability of increasing a valve's resistance before lumbar operation should prove this theory.

This commentary refers to the article doi: 10.1007/s00381-008-0788-0.

G. Shokouhi $(\bowtie)$

Tabriz University of Medical Sciences,

PO Box 51385-4516, Tabriz, Iran

e-mail: shokouhigh@yahoo.com 